\title{
De la seguridad e higiene \\ a la seguridad y salud: 50 años de prevención de riesgos laborales en España
}

\author{
Emilio Castejón ${ }^{1,2}$ \\ Fernando G. Benavides $3,4,5$ (1) 0000-0003-0747-2660 \\ ${ }^{1}$ Consultor en Prevención de Riesgos laborales, Barcelona, España. \\ ${ }^{2}$ Instituto Nacional de Seguridad y Salud en el Trabajo (1972-2015), Centro Nacional de Condiciones \\ de Trabajo, Barcelona, España. \\ ${ }^{3}$ Centro de Investigación en Salud Laboral, Barcelona, España. \\ ${ }^{4}$ CIBER de Epidemiología y Salud Pública, Barcelona, España. \\ 5IMIM-PSMar, Universitat Pompeu Fabra, Barcelona, España.
}

Fechas · Dates

Recibido: 2021.02.25

Aceptado: 2021.03.12

Publicado: 2021.04.15

\section{Correspondencia $\cdot$ Corresponding Author}

Fernando G. Benavides

E-mail: fernando.benavides@upf.edu 
El 9 de marzo de 2021 habrá cumplido 50 años nuestro referente nacional en prevención y salud en el trabajo, el actual Instituto Nacional de Seguridad y Salud en el Trabajo (INSST). Una edad para celebrar y para reflexionar sobre el camino andado, y encarar el que hay por delante hasta ser al menos centenario. Este es el doble objetivo de este comentario editorial.

Efectivamente, en los años sesenta del siglo pasado la siniestralidad laboral alcanzó en España cotas elevadísimas: eran habituales cifras de un millón de accidentes de trabajo con baja al año, que correspondían a índices de incidencia superiores a diez mil accidentes anuales por cada cien mil trabajadores, casi el triple que en la actualidad $^{(1)}$. Hoy hablaríamos de epidemia de lesiones por accidentes de trabajo. En definitiva, un coste sanitario y social que no se podía permitir un país que quería salir de la autarquía y conectar con las economías de los países occidentales. Eran tiempos de apertura internacional en una sociedad que salía de los años más duros de la dictadura franquista.

Una de las medidas más importantes para hacer frente a esta lamentable situación fue la aprobación de la Ordenanza General de Seguridad e Higiene en el Trabajo en $1971^{(2)}$, que sustituía al obsoleto Reglamento General de Seguridad e Higiene en el Trabajo de 1940, en el que podían leerse afirmaciones como que los riesgos profesionales eran la "secuela inevitable de la industria moderna". La Ordenanza vino a modernizar los conceptos recogiendo "la experiencia y avances técnicos logrados en las tres últimas décadas", y dotó a la Inspección de Trabajo, que ya existía desde 1906(3), de un instrumento con el que era posible mejorar notablemente la efectividad de sus actuaciones.

Pero quizás el antecedente más importante para la creación del Instituto Nacional de Seguridad e Higiene en el Trabajo sea la aprobación del Plan Nacional de Higiene y Seguridad en el Trabajo en $1971^{(4)}$, "...que comprenderá las... acciones... formativas,... de asesoramiento,...en las empresas,...de colaboración,... y acciones generales". La acción en las empresas incluía la "creación de servicios técnicos de seguridad en las empresas que cuentan con servicios médicos autónomos".

Las disponibilidades financieras del Plan fueron tan considerables, fruto del momento esplendido que vivía la recién unificada Seguridad Social en 1966, que en apenas cinco años se construyeron la mayor parte de los cincuenta Gabinetes Técnicos (uno por provincia) y tres Institutos Territoriales (el de Vizcaya fue construido posteriormente), y se contrataron centenares de profesionales que en su inmensa mayoría reunían dos características comunes: tenían una formación técnico-científica (médicos, ingenieros, químicos, arquitectos, aparejadores, psicólogos, pedagogos...) y estaban recién graduados. jEran jóvenes!

Pero es en plena transición a la democracia, y con los pactos de la Moncloa reestructurando un Estado que pasaba de la dictadura a la democracia, cuando se crea el Instituto Nacional de Higiene y Seguridad en el Trabajo (primero la higiene y luego la seguridad), mediante el Real Decreto-ley 36/78, de 16 de noviembre. Un acto en dos tiempos, pues hay que esperar cuatro años más, mediante el Real Decreto 577/82, para que se defina la estructura y las competencias del Instituto Nacional de Seguridad e Higiene en el Trabajo (cambia el orden y lo primero es la 
seguridad). Los órganos del nuevo Instituto eran los Centros Nacionales, los Gabinetes Técnicos Provinciales y los Centros de Investigación y Asistencia ${ }^{(5)}$.

Una estructura que dura bien poco pues, con la nueva organización territorial del Estado, en 1983 comenzarían las transferencias de los Gabinetes Técnicos Provinciales en Comunidades Autónomas, la cual culminaría en el año 2000 con la transferencia del Gabinete de Asturias. En ese momento el Instituto queda con su sede central en Madrid y cuatro centros especializados en Madrid, Sevilla, Bilbao y Barcelona, y centrado teóricamente en las tareas de investigación y formación, pero realmente dando apoyo a la Administración General del Estado en los temas de su competencia. En esas condiciones, privado en la práctica de las funciones de asistencia técnica a pequeñas y medianas empresas que representaron la principal actividad en su primera década de existencia, el Instituto se reorienta hacia la divulgación de lo aprendido en ese período mediante publicaciones como las Notas Técnicas de Prevención, los Documentos Técnicos, las Aplicaciones Informáticas para la Prevención y múltiples monografías sobre distintos aspectos preventivos.

Al mismo tiempo se modifica la orientación de la acción formativa, que al comienzo se centraba en cursos para trabajadores impartidos a través de los Gabinetes Técnicos Provinciales, para dedicarla fundamentalmente a la formación "superior" dirigida a la formación y perfeccionamiento de los técnicos de prevención. ¡Estaban a punto de llegar los Máster!

Pero los cambios continúan, nunca nos bañamos en el mismo agua que diría aproximadamente Heráclito, y con nuestra entrada en 1986 en lo que hoy es la Unión Europea, y la aprobación de la Directiva marco en 1989, se aprueba la consiguiente Ley de Prevención de Riesgos Laborales en 1995(6), en cuyo artículo 8 se define al Instituto como: "el órgano científico técnico especializado de la Administración General del Estado que tiene como misión el análisis y estudio de las condiciones de seguridad y salud en el trabajo, así como la promoción y apoyo a la mejora de las mismas". Una formulación que ha sido respaldada por las estrategias españolas de 2007-2012 ${ }^{(7)}$ y 2015-2020(8), pero sin que en la práctica haya producido cambios significativos, más allá del cambio reciente del nombre por "Seguridad y Salud en el Trabajo", acorde con la habitual en la Unión Europea, y la Agencia Europea de Seguridad y Salud en el Trabajo.

Mientras tanto, la dotación de personal técnico, la materia prima esencial del Instituto, se ha visto progresivamente reducida en el número de técnicos de los Centros Nacionales, que entre los años 2000 y 2019 pierden casi el 40\%, mientras los Servicios Centrales doblan su dotación. Parece deducirse de ello el progresivo abandono por parte de la Dirección de los Centros Nacionales, particularmente el de Barcelona, que ha pasado de ser el que tenía mayor dotación al que la tiene menor, habiendo visto reducida su plantilla en casi un $60 \%$.

Ante esta situación, que podemos calificar de crisis, no solo demográfica y de recursos, sino sobre todo de identidad, parece necesario abrir un debate, aprovechando este aniversario que nos muestra con sus luces y sombras la realidad del actual INSST, que pensamos debe reinventarse profundamente en una triple dirección. 
Por un lado, asumiendo plenamente la estructura federal del Estado, para lo que cuenta con Centros Nacionales, los cuales pueden renovarse en el marco de los proyectos europeos de Next Generation postpandémicos, en la dirección de la digitalización y la economía sostenible a los que las empresas se han de sumar, potenciando la colaboración público-privada y la coordinación con los institutos de las comunidades autónomas. Un ejemplo lo tenemos en el Centro Nacional de Medios de Protección de Sevilla, asumiendo el liderazgo en la certificación de los equipos de protección personal, especialmente mascarillas, cuyo papel preventivo ha sido y es crucial frente a la pandemia. Por supuesto más allá de su uso en el medio laboral, pero las fronteras entre lo laboral y lo ambiental hace tiempo quedaron diluidas, al igual que estamos experimentando estos días la continuidad entre la esfera laboral y personal con el teletrabajo.

En segundo lugar, para desarrollar su misión, como "órgano científico técnico especializado", tal como lo define la Ley de Prevención, debería introducir en su gobernanza una segunda dimensión que dé centralidad a la protección de la salud de las personas que trabajan, para balancear la dimensión que ha sido hasta ahora casi exclusiva, centrada en el apoyo al desarrollo normativo y su control, que ejerce la Inspección de Trabajo, la cual ha tenido un peso excesivo en la orientación estratégica en estos 50 años del INSST.

Por último, y no por ello menos importante, es imprescindible la constitución del INSST como un organismo autónomo, que le proporcione capacidad para disponer de un sistema de contratación de personal basado en una selección que valore la experiencia científica y profesional, adecuando los perfiles a los objetivos perseguidos, y que mediante convocatoria pública las candidaturas sean evaluadas por un comité independiente.

La alternativa, si no se adapta, es cerrarlo. Lo que seria una lástima pues, además, habría que crear otro INSST.

\section{Bibliografía}

1. Benavides FG, López-Ruiz M, Castejón E. Tendencia secular de las lesiones por accidentes de trabajo en España, 1904-2005. Arch Prev Riesgos Labor. 2008;11:141-7.

2. Orden de 9 de marzo de 1971 por la que se aprueba la Ordenanza General de Seguridad e Higiene en el Trabajo. BOE núm. 64, 16 de marzo de 1971.

3. Real Decreto del 1 de marzo de 1906, que organiza el Servicio de Inspección de Trabajo. Gaceta de Madrid no 63 del 4 de marzo de 1906.

4. Orden de 9 de marzo de 1971 por la que se aprueba el Plan de Higiene y Seguridad del Trabajo. BOE núm. 60, del 11 de marzo de 1971.

5. Real Decreto 577/1982, de 17 de marzo por el que se regulan la estructura y competencias del Instituto Nacional de Seguridad e Higiene en el Trabajo. BOE núm. 69, del 22 de marzo de 1982. 
6. Ley 31/1995, de Prevención de Riesgos Laborales. BOE del 10 de noviembre de 1995.

7. Estrategia Española de Seguridad y Salud en el Trabajo 2007-2012. [citado 30 Ene 2021]. Disponible en: https://www.insst.es/documents/94886/96076/Estrategia+Espa\%C3\%B1ola+de+SST++2007-2019+y+planes+de+acci\%C3\%B3n.pdf/ a1b9a7c1-c77d-4613-8a5f-5f7ec6fd4869?t=1533221941369.

8. Estrategia Española de Seguridad y Salud en el Trabajo 2015-2020. [citado 30 Ene 2021]. Disponible en: https://www.insst.es/documents/94886/211340/ ESTRATEGIA+SST+15_20.pdf/6ad555c4-d5d8-4ab 5-8c27-f576e1c$\mathrm{d} 6230 ? \mathrm{t}=1528113524934$. 